
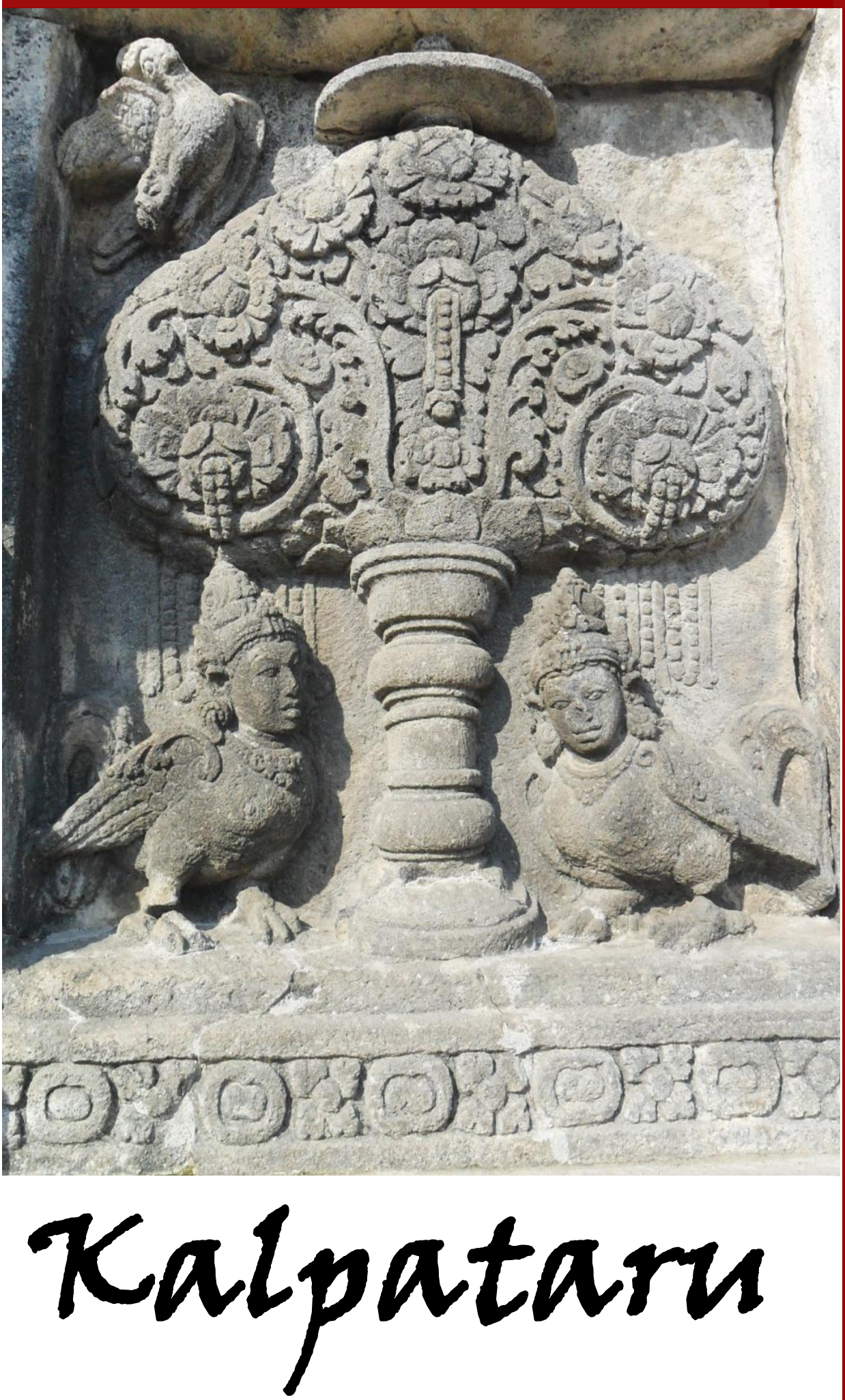

JURNAL SEJARAH DAN PEMBELAJARAN SEJARAH
Program Studi Pendidikan Sejarah Jurusan Pendidikan IPS

Fakultas Keguruan dan IImu Pendidikan Universitas Persatuan Guru Republik Indonesia Palembang
Nilai Budaya Masjid Jami' Sungai Lumpur Kelurahan II Ulu Palembang Sebagai Sumber Pembelajaran Sejarah

Maya Susanti, Muhamad Idris, Aan Suriadi

Analisis Konsep Gender Dalam UndangUndang Simbur Cahaya Sebagai Sumber Pembelajaran Sejarah

Ruli Annisa, Muhamad Idris, Kabib Sholeh

Perbedaan Model Pembelajaran Student Teams Achievement Divisions (STAD) dengan Model Pembelajaran Jigsaw Terhadap Hasil Belajar Siswa Pada Mata Pelajaran Sejarah di SMA Negeri 2 Mesuji

Taufik Sidiki Al-Haq, Nur Ahyani, Ida Suryani

Pengaruh Pemanfaatan Media Youtube Terhadap Hasil Belajar Siswa Mata Pelajaran Sejarah di SMK PGRI 2 Palembang

Riska Anggraini, Nur Ahyani, Ida Suryani

Pengaruh Metode Pembelajaran Daring Terhadap Hasil Belajar Siswa Pada Mata Pelajaran Sejarah di Kelas XI IPA SMA Shailendra Palembang

Christina Leovita Saragih, Nur Ahyani, Aan Suriadi

Pengembangan Media Pembelajaran Digital Bukti-bukti Bangunan Masjid Kuno di Palembang Berbasis Android Varokah Widiyanti, Eva Dina Chairunisa, Ahmad Zamhari

Hubungan Jawa-Melayu Dalam Dunia Arsitektur Melayu Sumatera Selatan Reyvaldi Uyun, Muhamad Idris, Ahmad Zamhari

Kondisi Politik Orde Baru di Gorontalo Tahun 1968-1998

Ferrari Yuliawati S, Suryo Ediyono

Nilai-nilai Sejarah dan Budaya Ikonografi Megalith di Lahat Sebagai Sumber Pembelajaran Sejarah Nasional Jainal Arifin, Sukardi, Dina Sri Nindiati

Minat Siswa Terhadap Sejarah dan Budaya Palembang di SMA Negeri 15 Palembang Febbi Astuti, Muhamad Idris, Kabib Sholeh 


\section{Kalpataru}

Jurnal Sejarah dan Pembelajaran Sejarah

Volume 7, Nomor 1, Juli 2021

\section{Chief Editor}

Drs. Sukardi, M.Pd.

\section{Editor}

Dr. Muhamad Idris, M.Pd.

Eva Dina Chairunisa, M.Pd.

Jeki Sepriady, S.Pd.

\section{Reviewer}

Dr. Tahrun, M.Pd.

Drs. Supriyanto, M.Hum.

Dra. Retno Purwati, M.Hum.

Dr. Nor Huda Ali, M.Ag., M.A.

Dr. Budi Agung Sudarman, S.S., M.Pd.

Dr. Purmansyah, M.A.
(Universitas PGRI Palembang)

(Universitas Sriwijaya Palembang)

(Balai Arkeologi Sumatera Selatan)

(Masyarakat Sejarawan Indonesia Sumsel)

(Balai Bahasa Provinsi Sumatera Selatan)

(Universitas Muhammadiyah Palembang)

\footnotetext{
Alamat Redaksi

Program Studi Pendidikan Sejarah

Fakultas Keguruan dan IImu Pendidikan Universitas PGRI Palembang

Telp. 0711-510043

Email: jurnalkalpatarusejarah@gmail.com

Website: https://jurnal.univpgri-palembang.ac.id/index.php/Kalpa
} 


\section{Kalpataru}

JURNAL SEJARAH DAN

PEMBELAJARAN SEJARAH

Terbit dua kali setahun pada Juli dan Desember

Diterbitkan oleh:

Program Studi Pendidikan Sejarah Jurusan Pendidikan IPS

Fakultas Keguruan

dan IImu Pendidikan

Universitas PGRI Palembang

\section{DAFTAR ISI}

Nilai Budaya Masjid Jami' Sungai Lumpur Kelurahan II Ulu Palembang Sebagai Sumber Pembelajaran Sejarah Maya Susanti, Muhamad Idris, Aan Suriadi.....

Analisis Konsep Gender Dalam Undang-Undang Simbur Cahaya Sebagai Sumber Pembelajaran Sejarah Ruli Annisa, Muhamad Idris, Kabib Sholeh $10-18$

Perbedaan Model Pembelajaran Student Teams Achievement Divisions (STAD) dengan Model Pembelajaran Jigsaw Terhadap Hasil Belajar Siswa Pada Mata Pelajaran Sejarah di SMA Negeri 2 Mesuji

Taufik Sidiki Al-Haq, Nur Ahyani, Ida Suryani. 19-27

Pengaruh Pemanfaatan Media Youtube Terhadap Hasil Belajar Siswa Mata Pelajaran Sejarah di SMK PGRI 2 Palembang

Riska Anggraini, Nur Ahyani, Ida Suryani. $28-36$

Pengaruh Metode Pembelajaran Daring Terhadap Hasil Belajar Siswa Pada Mata Pelajaran Sejarah di Kelas XI IPA SMA Shailendra Palembang

Christina Leovita Saragih, Nur Ahyani, Aan Suriadi. $37-42$

Pengembangan Media Pembelajaran Digital Bukti-bukti Bangunan Masjid Kuno di Palembang Berbasis Android Varokah Widiyanti, Eva Dina Chairunisa, Ahmad Zamhari .

\section{Gambar Cover:}

Pohon Kalpataru

Candi Prambanan

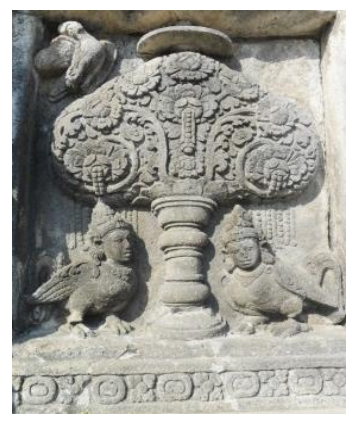

Koleksi: Muhamad Idris
Hubungan Jawa-Melayu Dalam Dunia Arsitektur Melayu Sumatera Selatan

Reyvaldi Uyun, Muhamad Idris, Ahmad Zamhari.

Kondisi Politik Orde Baru di Gorontalo Tahun 19681998

Ferrari Yuliawati S, Suryo Ediyono.

Nilai-nilai Sejarah dan Budaya Ikonografi Megalith di Lahat Sebagai Sumber Pembelajaran Sejarah Nasional Jainal Arifin, Sukardi, Dina Sri Nindiati.

Minat Siswa Terhadap Sejarah dan Budaya Palembang di SMA Negeri 15 Palembang

Febbi Astuti, Muhamad Idris, Kabib Sholeh. 77-82 


\title{
NILAI-NILAI SEJARAH DAN BUDAYA IKONOGRAFI MEGALITH DI LAHAT SEBAGAI SUMBER PEMBELAJARAN SEJARAH NASIONAL
}

\author{
Jainal Arifin \\ Mahasiswa Program Pendidikan Sejarah FKIP Universitas PGRI Palembang \\ Email: jainalarifin1818@gmail.com \\ Sukardi \\ Dosen Program Pendidikan Sejarah FKIP Universitas PGRI Palembang \\ Email: sukardipgri12@gmail.com \\ Dina Sri Nindiati \\ Dosen Program Pendidikan Sejarah FKIP Universitas PGRI Palembang \\ Email: dinamrsyid@gmail.com
}

\begin{abstract}
ABSTRAK
Lahatdikenal sebagai surganya megalith karena memiliki sekitar 1027 peninggalan megalith yang tersebar di 41 situs di Kabupaten Lahat, salah satunya ialah situs Padang Perigi. Permasalahan penelitian ini adalah bagaimana nilai-nilai sejarah dan budaya ikonografi megalith yang ada di Lahat khususnya situs Padang Perigi agar dapat dimanfaatkan sebagai sumber pembelajaran sejarah nasional. Tujuan penelitian ini adalah untuk mengetahui dan menganalisi nilai-nilai sejarah dan budaya ikonografi megalith di Lahat khususnya situs Padang Perigi. Penelitian ini menggunakan metode deskriptif kualitatif, dengan teknik pengumpulan data yaitu, observasi, wawancara, dokumentasi dan studi pustaka. Hasil penelitian ini adalah tentang ikonografi megalith, nilai sejarah, nilai budaya, dan nilai modernitas yang didapat dari 3 arca manusia dan 1 batu datar yang ada di situs Padang Perigi. Materi ini dapat dijadikan sebagai sumber pembelajaran sejarah nasional, karena terdapat dalam KD. 3.4. Memahami hasil-hasil dan nilai-nilai budaya masyarakat praaksara Indonesia dan pengaruhnya dalam kehidupan lingkungan terdekat.
\end{abstract}

Kata Kunci: Nilai, Sejarah, Megalith.

\section{A. PENDAHULUAN}

Lahat sejak dulu dikenal sebagai surganya megalith karena memiliki sekitar 1027 peninggalan megalith yang tersebar di 41 situs di seluruh Kabupaten Lahat, Sumatera Selatan. Atas catatan itu, pada tahun 2012 Kabupaten Lahat sebagai kabupaten tertua di Sumatera Selatan mendapat penghargan Museum Rekor Dunia Indonesia (MURI) sebagai daerah dengan peninggalan megalith paling banyak di seluruh Indonesia (Iskandar, 2020:1). Situs Padang Perigi misalnya yang terletak di desa Padang Perigi Kecamatan Tanjung Tebat Kabupaten Lahat. Di situs tersebut terdapat 4 megalith yaitu 3 arca manusia dan 4 batu datar. Ikonografi arca megalith manusia 1 seperti orang sedang bersujud yang hanya terlihat bagian kirinya saja dengan ukuran panjang 180 $\mathrm{cm}$, lebar $140 \mathrm{~cm}$, tinggi $90 \mathrm{~cm}$, arca manusia 2 hanya terlihat bagian kaki kanan dan badan sedang berjongkok dengan ukuran panjang 210 , lebar 140, tinggi $90 \mathrm{~cm}$, manusia 3 hanya terlihat bagian bahu tanpa kepala dengan ukuran panjang $90 \mathrm{~cm}$, lebar $55 \mathrm{~cm}$, tinggi $16 \mathrm{~cm}$ (Sudaryadi, 2016:13). Pada megalith tersebut terdapat nilai-nilai sejarah yang banyak terkandung di dalamnya, selain itu juga terdapat nilai budaya yang pada megalith tersebut.

Dari uraian di atas peneliti tertarik untuk meneliti tentang nilai-nilai sejarah dan budaya megalith di Lahat, yang mengangkat judul "NilaiNilai Sejarah dan Budaya Ikonografi Megalith di Lahat Sebagai Sumber Pembelajaran Sejarah Nasional". Peneliti mengambil judul ini karena kurangnya pemahaman siswa dan masyarakat terhadap sejarah megalith yang ada di Lahat. 


\section{Kalpataru, Volume 7, Nomor 1, Juli 2021 (68-76)}

Hasil penelitian ini diharapkan nantinya dapat mengungkap nilai-nilai sejarah dan budaya ikonografi megalith yang ada di Lahat, guna membantu para siswa, guru dan masyarakat agar lebih mudah memahami nilai-nilai sejarah dan budaya yang terkandung di dalam batu megalith yang ada di Lahat. Peneliti juga berharap, dengan adanya penelitian ini dapat membantu dan mengangkat nilai sejarah dan budaya yang ada di Desa Padang Perigi sebagai sumber materi pembelajaran sejarah untuk kelas $\mathrm{X}$, guru, serta masyarakat melalui batu megalith.

Berdasarkan penelitian tersebut, maka masalah dalam penelitian ini dirumuskan sebagai berikut:

1. Bagaimana nilai-nilai sejarah dan budaya ikonografi megalith di Lahat dapat menjadi sumber pembelajaran sejarah nasional?

2. Bagaimana meningkatkan pemahaman masyarakat terhadap nilai-nilai sejarah megalith yang ada di Lahat?

Berdasarkan rumusan masalah, maka tujuan yang ingin dicapai dalam penelitian adalah:

1. Untuk mendeskripsikan nilai-nilai sejarah dan budaya ikonografi megalith di Lahat sebagai sumber pembelajaran sejarah nasional.

2. Untuk meningkatkan pemahaman masyarakat terhadap nilai-nilai sejarah megalith yang ada di Lahat.

\section{B. METODE PENELITIAN}

Metode yang digunakan dalam penelitian ini menggunakan metode deskriptif kualitatif (Sugiyono, 2017:12).

Data dan Sumber Data. Observasi: observasi dalam penelitian ini dilakukan di Situs Padang Perigi. Wawancara: dalam penelitian ini, peneliti melakukan dengan Mario Andramartik selaku ketua Panoramic of Lahat, Sukandar selaku ketua adat Desa Padang Perigi, dan Yustam selaku penjaga situs megalith. Dokumentasi: foto 3 arca dan 1 batu datar megalith yang di Situs Padang Perigi.

Teknik Pengumpulan Data. Observasi Lapangan: observasi lapangan dalam penelitian ini dilakukan di areal persawahan bapak Yustam. Wawancara mendalam: dalam penelitian ini, peneliti melakukan wawancara dengan bapak Mario Andramartik selaku ketua Panoramic of Lahat.

Validasi Data. Triangulasi Sumber: dalam penelitian ini triangulasi sumber yang akan digali berupa informan yaitu sejarawan, balai arkeologi, pemangku adat, arsip, jurnal ilmiah tingkat nasional dan buku referensi standar sejarah. Triangulasi Metode: triangulasi metode yang digunakan dalam penelitian ini yaitu menggunakan metode pengumpulan data berupa wawancara, observasi, dan dokumentasi.

Teknik Analisis Data: analisis data yang dilakukan dalam penelitian ini yaitu menggunakan analisis model interaktif, analisis model interaktif terdiri atas tiga jalur kegiatan yang terjadi secara bersamaan, yaitu redaksi data, penyajian data, dan penarikan kesimpulan/verifikasi (Maryaeni, 2012:75).

\section{HASIL DAN PEMBAHASAN}

Penelitian ini dilaksanakan di Situs Padang Perigi yang dimulai pada tanggal $20 \mathrm{Mei}$ 2021 sampai dengan 30 Mei 2021. Adapun objek dari penelitian ini adalah 3 arca manusia dan 1 batu datar. Dalam pemilihan situs Padang Perigi sebagai lokasi penelitian ini karena peneliti mendapati adanya nilai-nilai sejarah dan budaya yang terkandung di dalam situs Padang Perigi, jarak lokasi situs Padang Perigi ini dengan pemukiman warga berjarak kurang lebih 1 kilometer.

Situs Padang Perigi secara administrasi terletak di Desa Padang Perigi, Kecamatan Tanjung Tebat, Kabupaten Lahat, Provinsi Sumatera Selatan. Secara geografis berada pada koordinat $03^{\circ} 59^{\prime} 40^{\prime \prime}$ Lintang Selatan dan 10326'35.87" Bujur Timur di ketinggian 443 meter di atas permukaan laut (Sudaryadi, 2016:15). Menurut bapak Yustam (ketua adat desa Padang Perigi), asal-usul desa berasal dari permukaan lahan sawah 16 orang dari Desa Mutar Alam, Kecamatan Kota Agung. Mereka membangun siring (parit irigasi) untuk mengairi areal persawahan, siring atau parit irigasi ini dibuat mulai dari hulu sungai Mata Lintang sampai lokasi sawah, sepanjang kurang lebih 5 kilometer. Di areal ini, mereka membagi areal menjadi 16 bagian sawah, sesuai dengan 


\section{Kalpataru, Volume 7, Nomor 1, Juli 2021 (68-76)}

jumlah orang yang membangun parit. Masingmasing orang mendapat satu bidang sawah dengan ukuran kurang lebih $150 \times 150$ meter. Selanjutnya tiap orang boleh membawa satu orang lagi dan mendapatkan lahan $75 \times 150$ meter. Sampai sekarang areal persawahan masih dimanfaatkan oleh masyarakat, meski sudah terjadi beberapa kali pergantian kepemilikan. Kata Padang Perigi diambil dari nama tempat di mana mereka datang yaitu areal Perigi. Pada saat itu, areal persawahan masih berupa padan ilalang, karena itu disebut Padang Perigi inilah sekarang jadi nama resmi desa (Sudaryadi, 2016:16). Jadi toponim Desa Padang Perigi berasal dari areal siring atau parit yang kemudian menjadi sebuah nama desa yaitu Padang Perigi.

Megalith yang terdapat di situs Padang Perigi berupa 3 arca manusia dan 1 batu datar, megalith ini termasuk dalam pengawasan Balai Pelestarian Cagar Budaya Jambi. Situs ini berada di sawah bapak Yustam, sehingga Balai Pelestarian Cagar Budaya Jambi mempercayakan bapak Yustam untuk merawat dan menjaga situs tersebut agar tidak rusak atau terhindar dari tangan jahil manusia (vandalisme). Arca manusia yang pertama dalam kondisi orang yang sedang bersujud namun hanya terlihat pada bagian kirinya saja, dengan ukuran panjang $180 \mathrm{~cm}$, lebar $140 \mathrm{~cm}$, tinggi $90 \mathrm{~cm}$. Arca manusia II berada dikelokan parit terlihat hanya pada bagian kaki kanan dan badan sedang berjongkok pada kakinya menggunakan gelang-gelang. Ukurannya adalah panjang $210 \mathrm{~cm}$, lebar $140 \mathrm{~cm}$, dan tinggi $90 \mathrm{~cm}$. Arca manusia III hanya terlihat pada bagian bahu tanpa kepala berukuran panjang 90 $\mathrm{cm}$, lebar $55 \mathrm{~cm}$, tinggi $16 \mathrm{~cm}$, situs ini terdapat di tengah persawahan warga sehingga banyaknya rerumputan yang mengelilingi di sekitar megalith. Arca manusia II yang berada di kelokan parit, keadaan tersebut membuatnya sangat rentan terkena erosi air parit apabila air parit sedang meluap, sehingga ketika peneliti datang ke lokasi situs, pahatan yang terdapat pada arca megalith sudah sedikit memudar akibat erosi air. Kepala arca manusia III sudah dipindahkan dari tempat awal ditemukannya, semula kepala tersebut berada di dalam parit akibat menggelinding terlepas dari badannya, menurut warga setempat penyebabnya terpisahnya kepala arca III dengan badan nya tersebut diakibatkan ulah kerbau yang menggosokkan badannya ke kepala tersebut, sekarang arca manusia III sudah dipindahkan di bawah dangau (pondok) milik bapak Yustam. Sementara arca I dan badan arca III masih berada di tempat awal penemuannya.

Situs Padang Perigi berada di tanah Pasemah Kabupaten Lahat yang notabene suatu wilayah banyak ditemukannya situs megalith, bahkan pada tahun 2012 Kabupaten Lahat mendapat Rekor MURI sebagai pemilik situs terbanyak dan berjuluk Bumi Seribu Megalith (Andramartik, 2017:1). Megalith Pasemah yang tersebar di wilayah Kabupaten Lahat dan Kota Pagaralam menurut para ahli ditenggarai berasal dari kebudayaan besar yang disebut sebagai Austronesia. Diaspora bangsa Austronesia ke wilayah Asia Tenggara diperkirakan berlangsung antara kurun 2500 SM-1500 SM yang kemudian menyebabkan tersebarnya tinggalan megalith di kawasan Asia Tenggara. Persebaran tinggalan budaya megalith ini meliputi wilayah Laos, Tonkin, Indonesia, Pasific serta Polinesia.

Situs Padang Perigi di ekskavasi pada tahun 2015 oleh Balai Pelestarian Cagar Budaya yang dipimpin oleh bapak Agus Sudaryadi. Sebelumnya telah terjadi peninjauan pada tahun 2014 atas laporan ketua Panoramic of Lahat, yaitu bapak Mario Andramartik. Kondisi pada saat ekskavasi berbeda pada saat peninjauan yang dilakukan pada tahun 2014, di mana tanah disekitarnya kering. Pada saat penyelamatan ekskavasi penyelamatan terdapat hamparan batang padi yang berumur sekitar 2 bulan, sehingga memerlukan pencabutan beberapa batang padi yang terkena ekskavasi. Di parit juga mengalir air lebih banyak. Ekskavasi situs Padang Perigi menggunakan sistem grid dan penggalian menggunakan teknik spit dan lot. Sistem grid ialah dengan menarik tali sehingga saling menyilang, teknik spit dan lot yaitu menggali tanah dengan interval $20 \mathrm{~cm}$ dengan batas kedalaman samapai $60 \mathrm{~cm}$. Ekskavasi situs Padang Perigi dilaksanakan dengan menggali 14 kotak. Kotak gali sebanyak 8 kotak dengan teknik spit, dan 6 kotak dengan teknik lot. 


\section{Kalpataru, Volume 7, Nomor 1, Juli 2021 (68-76)}

Kedalaman galian sesuai dengan batas terbawah dari arca. Dengan demikian tanah yang digali hanya tanah yang menimbun arca dan tidak mengganggu tanah aslinya. Tanah yang menimbun arca-arca itu diperkirakan berasal dari aktivitas bersawah yang berlangsung puluhan tahun. Ekskavasi berhasil memperjelas kondisi arca-arca megalith yang tadinya tertimbun tanah selama penggalian tidak ditemukan benda-benda arkeologis selain arca manusia, kepala arca dan batu datar.

Situs megalith Padang Perigi berada di wilayah Pasemah yang dihuni oleh suku Basemah. Masyarakat suku Basemah yang hidup disekitar gunung Dempo dan Bukit Barisan sebagian besar merupakan petani dengan mengelola kebun. Tanaman pokok yang ditanam masyarakat ialah kopi, kopi yang terkenal dari daerah ini ialah kopi Semendo, yang berjarak kurang lebih 20 kilometer dari situs Padang Perigi. Kopi Semendo adalah salah satu kopi yang paling dicari oleh para penikmat kopi. Sedangkan tanaman lainnya adalah sayuran, sayur yang ditanam berupa kubis, wortel, cabe, daun bawang, seledri, dan lain-lain.

Bahasa yang digunakan masyarakat di sekitar situs megalith ialah bahasa Melayu Vernakular, di mana bahasanya hampir sama dengan bahasa Melayu pada umumnya, namun pada pengucapan menggunakan dialek yang berbeda, konsonaan setiap katanya didominasi dengan huruf $\mathrm{E}$, contoh katanya ialah dimane, kemane, makmane namun aksen masyarakat di sekitar megalith situs Padang Perigi sedikit khas dengan daerah yang lain, sehingga dapat dikenali asal orang tersebut melalui aksen bicaranya.

Pengetahuan masyarakat mengenai megalith situs Padang Perigi cukup beragam, ada yang sekedar tahu, namun banyak juga banyak yang telah paham mengenai situs megalith tersebut. Bagi masyarakat yang belum paham beranggapan situs megalith tersebut ialah sisa peninggalan Si Pahit Lidah atau Serunting Sakti yang dikutuk karena membangkang perintahnya. Untuk masyarakat yang telah paham sejarah, memaknai situs megalith Padang Perigi tersebut ialah sebagai hasil kebudayaan masyarakat zaman
Megalitikum yang menjadi bukti kemajuan masyarakat pada zaman itu.

Melihat pahatan yang ada di situs megalith Padang Perigi mengindikasikan sudah adanya kemajuan teknologi pada masa itu, terlihat pada arca manusia III bagian kanan sedang memegang senjata yang mirip bumerang dan pada kaki menggunakan gelanggelang kaki. Pemakaian gelang-gelang kaki juga terdapat di arca-arca megalith di Lahat. Gelanggelang itu kemungkinan terbuat dari perunggu. Kemiripan-kemiripan itu kemungkinan karena memang arca-arca Padang Perigi sezaman dengan arca megalith Lahat lainnya.

Agama yang dianut masyarakat di sekitar situs Padang Perigi mayoritas ialah Islam, karena di sini tidak dipengaruh oleh kebudayaan Hindu dan Buddha sehingga aliran Islam yang ada di sini tidak terakulturasi dengan kebudayaan sebelumnya. Agama terdahulu masyarakat atau pada masa nenek moyang mereka menganut ajaran Dinamisme dan Animisme, di mana masyarakat masa itu menyembah batu serta pepohanan yang dianggap berkekuatan magis sebagai ritual pemujaan roh nenek moyang.

Sistem organisasi masyarakat di desa Padang Perigi ini dipimpin oleh seorang kepala desa. Di sini sistem bermasyarakatnya ialah gotong royong, di mana setiap pekerjaan dilakukan dengan bersama-sama, seperti membajak sawah, panen padi, panen kopi, membangun jalan dan lain-lain, semuanya dilakukan bersama-sama masyarakat sekitar. Untuk menjalin keakraban antar tetangga di sini ada budaya yang bernama Pantauan, budaya Pantauan ini ialah warisan nenek moyang secara turun temurun, di mana pada saat ada yang menikah dan perayaan Idul Fitri, dilakukan tradisi Pantauan dari rumah kerumah warga untuk acara makan bersama, tentunya tradisi ini bermanfaat bagi ajang silaturahmi dan kerukunan masyarakat di sekitar situs Padang Perigi. 
Pembahasan

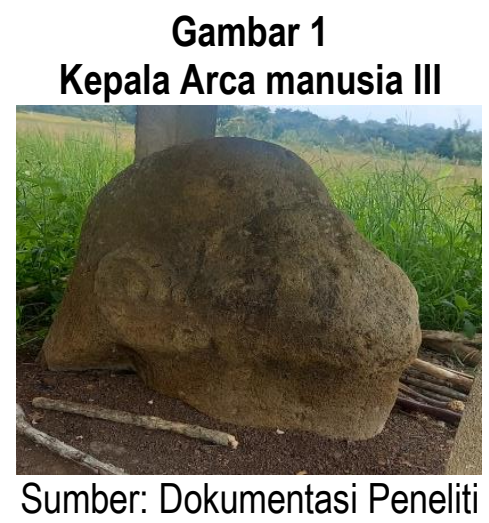

Megalith yang ada di situs Padang Perigi terdapat 3 arca manusia dan 1 batu datar. Tiga arca manusia yang dapat diidentifikasi sebagai peninggalan megalith. Arca-arca tersebut selanjutnya diberi nama sebagai arca manusia I, arca manusia II, dan arca manusia III. Keletakannya membentuk segitiga. Arah hadap arca-arca tersebut mengarah ke bagian dalam segitiga. Di dalam segitiga terdapat batu-batu datar. Diperkirakan batu-batu datar itu menjadi bagian dari upacara pemujaan yang dilakukan pada arca-arca manusia. Arca manusia I dan II tidak utuh menggambarkan bentuk manusia. Kedua arca tidak mempunyai kepala dan dipahatkan sebagian saja, yaitu badan, satu tangan, dan satu kaki. Bentuk arca yang setengah bagian tidak umum di situs-situs megalith Lahat, itu menandakan sebagai arca yang belum selesai atau ada tujuan lainnya. Berdasarkan bagian-bagian batu yang belum dipahat, menunjukkan tidak mungkin untuk memahat batu itu menjadi manusia utuh. Arca manusia III mempunyai komponen lengkap seperti manusia, yaitu mempunyai kepala, badan, dua tangan, dan kaki. Kepala arca tambah tidak proporsional apabila dibandingkan dengan badannya karena berukuran sangat besar, lehernya pun tampak lebar, pada bagian muka terdapat hidung yang telah aus dan pahatan yang memanjang pada dahi. Terdapat dua telinga yang besar dan di belakang kepala dekat leher terdapat bagian yang menonjol, bentuk yang menonjol dibagian belakang itu mirip dengan arca-arca di situs Tinggi Hari dan situs Tanjung Sirih. Bentuk yang menonjol diperkirakan sebagai topi masih menjadi pertanyaan, karena mengapa daun-daun telinga dari arca-arca itu kelihatan, padahal kalo menggunakan topi harusnya tertutup. Selain itu adanya pahatan panjang pada dahi seolah-olah menggambarkan adanya pengikat rambut. Atribut pada arca manusia III pada bagian tangan kanan sedang memegang senjata yang mirip bumerang dan pada bagian kaki menggunakan gelang-gelang kaki. Pemakaian gelang-gelang kaki terdapat di arca-arca megalith di Lahat. Gelang-gelang itu kemungkinan terbuat dari perunggu. Kemiripankemiripan itu kemungkinan karena memang arca-arca Padang Perigi sejaman dengan arca megalith Lahat lainnya.

Keberadaan arca-arca manusia di situs Padang Perigi belum diketahui berkaitan dengan benda-benda yang lainnya. Namun menurut infomasi, tidak jauh dari lokasi terdapat lesung batu. Berdasarkan kepada temuantemuan arca di situs lainnya, maka arca-arca ini tentunya dibuat oleh kelompok yang mendiami lokasi tersebut. Kemungkinan setiap kelompok masyarakat membuat arca-arca manusia sebagai objek pemujaan. Pembuatan arca ditujukan agar arwah nenek moyang memasuki arca yang dipuja dan dapat memberikan keberkahan bagi yang hidup. Atribut arca mungkin menggambarkan sosok para pria yang menggunakan topi, kalung, gelang-gelang pada tangan dan kaki dalam kehidupan sehariharinya.

\section{Arca Manusia I}

Arca manusia ini hanya dipahat pada badan sebelah kiri. Bagian kanan arca masih belum mengalami pengerjaan. Orientasi batu mengarah ke Utara-Selatan. Posisi arca menelungkup dengan kaki kiri dalam posisi berlutut, seperti orang sedang bersujud. Bagian atas yang tidak berbentuk kepala menghadap ke bawah. Tangan kiri melipat di bawah dada seperti sedang memeluk sesuatu. Arca manusia terlihat agak gemuk, ukuran arcanya memiliki panjang $202 \mathrm{~cm}$, lebar $132 \mathrm{~cm}$ dan tingginya 78 $\mathrm{cm}$. Arca manusia ini menggambarkan seakanakan seperti orang yang sedang menyembah sesuatu, hal itu berelevansi dengan kepercayaan yang ada di sekitar situs Padang Perigi yang menganut sistem kepercayan 


\section{Kalpataru, Volume 7, Nomor 1, Juli 2021 (68-76)}

Animisme. Arca ini hanya dipahat sebagian, itu mematahkan anggapan atau mitos yang berkembang di lingkungan masyarakat, yaitu arca-arca tersebut ialah hasil kutukan dari Serunting sakti atau biasa dikenal dengan $\mathrm{Si}$ Pahit Lidah.

\section{Arca Manusia II}

Arca manusia II hanya dikerjakan pada badan sebelah kanan. Sebelah kiri arca terlihat belum mengalami pengerjaan atau pembentukan. Orientasi arca manusia menghadap ke arah Barat Laut. Posisi arca dalam posisi jongkok dan badannya membungkuk ke depan tanpa kepala. Tangan kanan mempunyai jari-jari memegang benda seperti Gada. Gelang-gelang terdapat di bagian kaki kanan bersusun enam. Ukuran arca adalah panjang $191 \mathrm{~cm}$, lebar $126 \mathrm{~cm}$ dan tingginya 86 $\mathrm{cm}$. Arca manusia II ini telah menggunakan perhiasan pada gelang-gelang kaki kanan yang bersusun enam buah, hal itu memperlihatkan bahwa tingkat peradaban manusia megalith Padang Perigi sudah sangat tinggi karena mereka telah mengenal aksesoris dan fashion dalam berpakaian pada masa itu. Tangan kanan yang memegang benda seperti Gada menggambarkan kegagahan dan keberanian masyarakat pada masa itu, serta kewibawaan seorang pemimpin yang mampu memimpin organisasi masyarakat (kepala suku), hal itu memiliki korelasi dengan watak masyarakat suku Basemah yang tertulis dalam buku Jumhari yang berjudul "Identitas Kultural Bangsa Basemah" yang menyebutkan orang Basemah adalah orang yang mandiri dan merdeka, Basemah selalu menjaga dan memelihara kedaulatan mereka dari penguasa regional, baik Majapahit di Palembang dan Banten di Lampung, bahkan Kesultanan Palembang mengungkap orang Basemah sebagai sahabat dengan memberikan gelar kehormatan sebagai "Sindang Merdika" yang artinya adalah penjaga perbatasan.

\section{Arca Manusia III}

Arca manusia III ini tidak mempunyai kepala karena telah putus hanya sebatas leher, kepalanya berhasil ditemukan berjarak 17 meter dari badannya. Arca manusia menghadap kearah Tenggara. Arca dalam posisi jongkok bertumpu pada lutut kanan, lutut kiri agak maju ke depan, pada kaki kanan terdapat hiasan seperti gelang-gelang yang tersusun berjumlah 6 buah. Badan arca dalam posisi tegak. Tangan kanan berada di depan dada menggenggam sebuah benda berbentuk panjang melengkung mirip "bumerang", tangan kiri terlipat di sisi kiri badan dengan siku berada di bawah sedikit ke belakang tubuh arca. Badan arca bertubuh agak gemuk. Arca berukuran panjang $102 \mathrm{~cm}$, lebar $95 \mathrm{~cm}$ dan tinggi $64 \mathrm{~cm}$. Pada bagian lutut sebelah kiri mengalami kerusakan, karena ada bongkahan yang terpisah dari arca, disinyalir bongkahan tersebut bagian dari arca manusia III. Arca manusia III yang menggenggam sebuah benda bentuk panjang melengkung yang mirip bumerang disinyalir adalah sebuah gambaran seorang manusia yang sedang memegang arit untuk menjawat padi, hal itu tentunya sangat berkaitan dengan keadaan yang sekarang di mana daerah di sekitar situs Padang Perigi merupakan daerah penghasil beras terbaik yang ada di Kabupaten Lahat. Jadi bisa ditarik kesimpulan bahwa mata pencarian masyarakat di sekitar situs Padang Perigi dari masa megalithikum sampai dengan sekarang basisnya ialah daerah persawahan. Badan arca yang gemuk dan berposisi jongkok bertumpu pada lutut kanan seakan-akan menggambarkan sosok seorang pengawal yang tegas, patuh, serta taat terhadap pemimpinnya, disinyalir arca manusia III ini adalah sosok pembantu kepala suku, di mana pada masa itu telah mengenal organisasi masyarakat yang dipimpin oleh kepala suku.

\section{Arca Kepala Manusia III}

Arca kepala manusia III awalnya berada di dalam parit sebelah Timur Laut dengan jarak sekitar 17 meter dari badannya. Menurut informasi, kejadian itu disebabkan adanya seseorang yang akan membeli dan kemudian membawanya ke suatu tempat. Namun demikian, usaha tersebut tidak berhasil karena kepala yang sangat berat sehingga sulit untuk dipindahkan, meskipun oleh beberapa orang. Hal itu juga di alami oleh tim BPCB Jambi ketika akan mengamankan kepala arca ke bawah pondok. Tenaga berjumlah 10 orang dewasa 


\section{Kalpataru, Volume 7, Nomor 1, Juli 2021 (68-76)}

tidak dapat menggerakkan kepala arca itu. Usaha untuk memindahkan baru berhasil dengan menggunakan katrol atau bambu sebagai relnya. Kepala arca memekai penutup kepala berbentuk bulat dan memanjang di bagian belakang sampai pada bagian leher. Wajah arca telah aus (telah terkikis) namun masih menunjukkan bagian mata dan hidung, telinga kiri dan kanan masih terlihat jelas. Dagu kepala arca agak sedikit maju, sehingga wajah arca agak sedikit mendongak ke atas. Kepala arca berukuran tinggi $70 \mathrm{~cm}$ dan lebar $61 \mathrm{~cm}$. Bentuk kepala arca seperti itu mempunyai kemiripan dengan arca-arca manusia yang berada di situs Tinggi Hari dan situs Tanjung Sirih. Di depan arca manusia III terdapat batubatu alam yang berukuran besar dan kecil, batubatu itu bertebaran tidak beraturan. Arca kepala manusia III ini terlihat seakan-akan memakai helm atau pelindung kepala, hal itu menggambarkan sosok ksatria masa lalu yang siap bertempur menghadapi lawan-lawannya.

\section{Batu Datar}

Batu datar ini merupakan batu-batu alam yang ditemukan di sekitar arca-arca tanpa mengalami pembentukan oleh manusia. Bentuknya berbagai macam dengan ukuran yang berbeda-beda. Batu-batu itu berada di depan arca manusia III berjumlah 5 batu, batu yang paling besar berukuran panjang $110 \mathrm{~cm}$ dan lebar $98 \mathrm{~cm}$, sedangkan batu yang paling kecil berukuran panjang $40 \mathrm{~cm}$ dan lebar $13 \mathrm{~cm}$. Di dekat arca manusia II terdapat satu batu yang berukuran panjang $96 \mathrm{~cm}$ dan lebar $69 \mathrm{~cm}$. Diperkirakan keberadaan batu-batu alam tersebut merupakan bagian dari upacara pemujaan.

\section{Nilai-Nilai Sejarah}

Nilai-nilai sejarah megalith situs Padang Perigi merupakan hal-hal yang dianggap penting dan bermanfaat bagi ilmu kesejarahan. Umur arca megalith yang ada di situs Padang Perigi menurut Balai Pelestarian Cagar Budaya diperkirakan berumur 1500-2500 SM (Andramartik, 2017:2). Arca yang terdapat di situs Padang Perigi banyak terdapat kemiripan dengan situs-situs wilayah Lahat dan Pagaralam maupun yang ada di mancanegara, di wilayah Lahat arca kepala manusia III memiliki kemiripan dengan arca-arca manusia yang ada di Situs Tinggi Hari dan Tanjung Sirih. Keberadaan arca-arca di Situs Padang Perigi mengindikasikan pada masa lalu telah berlangsung kegiatan keagamaan dengan mendirikan bangunan megalith. Pada masa itu diperkirakan arca-arca di situs Padang Perigi tersebut digunakan untuk media pemujaan roh nenek moyang atau biasa disebut dengan sistem kepercayaan Animisme. Masyarakat sudah melakukan hal-hal yang religius dan merupakan pedoman dalam kehidupan seharihari, kepercayaan tersebut bukan hanya mengatur kehidupan, melainkan juga mempengaruhi dalam pembuatan atau meletakkan bangunan sakral. Melalui pendirian bangunan ini diharapkan roh nenek moyang di dalam arwah memperoleh ketentraman, sehingga dapat memberikan kesejahteraan dan kesuburan bagi masyarakat pendukungnya. Nenek moyang sebagai sumber pemujaan dianggap bersemayam di puncak gunung (Poesponogoro \& Notosusanto, 2010:247). Oleh karena itu gunung Dempo dianggap sebagai tempat suci. Dari gunung itulah air keluar dan memberikan kehidupan yang lebih baik bagi sawah dan ladang, binatang piaraan, maupun semua makhluk hidup di dunia. Namun sekarang cara pandang masyarakat disekitar situs megalith Padang Perigi mulai terbuka dengan ajaran Tauhid yaitu agama Islam yang mulai masuk ke daerah Pasemah pada abad ke$15 \mathrm{M}$. Hal itu dibuktikannya dengan tidak digunakannya arca-arca megalith yang ada di situs Padang Perigi sebagai tempat yang sakral sehingga dipakai untuk tempat pemujaan roh nenek moyang atau masyarakat daerah Lahat mengenalnya dengan nama tradisi Bepintak, di mana biasanya masyarakat datang untuk berdoa agar dikabulkan permintaannya, apabila sudah terkabul maka masyarakat tersebut akan kembali untuk mengadakan syukuran.

\section{Nilai Budaya}

Nilai budaya merupakan nilai yang ada dan berkembang dalam masyarakat. Karena nilai budaya adalah tingkat pertama kebudayaan ideal atau adat istiadat. Nilai budaya merupakan lapisan yang paling tidak 
terwujud dan ruangnya luas. Jadi nilai budaya adalah sesuatu yang sangat berpengaruh dan dijadikan pedoman atau rujukan bagi kelompok masyarakat yang ada di sekitar situs Padang Perigi. Pada perkampungan budaya megalith diperkirakan terdapat beberapa pusat upacara yang mewakili kelompok masyarakat. Adanya kemungkinan pendirian bangunan megalith mewakili satu keluarga dan juga mewakili satu kelompok yang lebih besar seperti desa atau kampung. Pendirian bangunan megalith di atas perbukitan menunjukkan kesamaan pemikiran adanya konsep bahwa arwah nenek moyang berada di tempat yang tinggi. Begitu pula adanya kemudahan masyarakat dahulu mendapatkan batu-batu megalith yang dijadikan bangunan pemujaan. Sedangkan bangunan arca megalith yang ada di situs Padang Perigi menunjukkan bahwa kegiatan ritual tidak hanya dilakukan di wilayah yang tinggi namun dapat dilakukan dengan memanfaatkan batu-batu megalith yang ada di Padang Perigi. Pemujaan ditujukan agar masyarakat penganut budaya megalith memperoleh keberhasilan dalam mata pencarian dibidang pertanian dan juga perlindungan dari segala marabahaya yang mengancam. Aksesoris atau pernak-pernik yang melekat pada megalith arca II dan III mengindikasikan begitu besarnya hasil kebudayaan pada masa itu karena telah mengenal fashion dalam berpakaian.

\section{Nilai Modernitas}

Nilai modernitas adalah peristiwa sejarah mengenai kemajuan dan teknologi yang berkembang di situs Padang Perigi. Jika melihat hasil temuan-temuan di daerah Pasemah khususnya daerah Pagaralam, megalith yang ditemukan cendrung polos atau tidak memiliki corak serta pernak-pernik seperti gelang yang melekat pada pahatan megalith arca II dan III, hal tersebut mengidentifikasikan bahwa kemajuan peradaban di daerah Padang Perigi ini lebih tinggi dibanding daerah lainnya. Pernak-pernik seperti gelang yang melekat pada megalith mengindikasikan masyarakat pada masa itu telah mengenal aksesoris serta fashion dalam berpakaian (Rr.Triwujani, 2018:115). Diperkirakan alat yang digunakan untuk memahat megalith ialah alat dari perunggu yang kemungkinan didapat dari migrasi daratan Asia. Hal tersebut membuktikan bahwa modernitas yang terjadi di situs Padang Perigi telah melakukan hubungan dengan kebudayaan luar atau karena adanya migrasi dari daratan Asia. Dengan bentuk pahatanpahatan perhiasan dan alat perunggu tersebut dapat dilihat bentuk kehidupan duniawi yang lebih ditonjolkan dan tentunya hal tersebut bertolak belakang dengan kebutuhan kehidupan gaib.

\section{Relevansi Situs Padang Perigi Sebagai Sumber Pembelajaran Sejarah Nasional}

Materi sejarah nasional yang terkait dalam penelitian ini adalah zaman prasejarah yang tertuang dalam silabus pembelajaran terdapat pada standar kompetensi: 3 . Memahami, menerapkan, dan menganalisis pengetahuan faktual, konseptual, prosedural berdasarkan rasa ingin tahunya tentang ilmu pengetahuan, teknologi, seni, budaya, dan humaniora dengan wawasan kemanusian, kebangsaan, kenegaraan, dan peradaban terkait fenomena dan kejadian, serta menerapkan pengetahuan prosedural pada bidang kajian yang spesifik sesuai dengan bakat dan minatnya untuk memecahkan masalah. Kompetensi Dasar yang sesuai pada penelitian ini terdapat pada poin: 3.4. Memahami hasilhasil dan nilai-nilai budaya masyarakat praaksara Indonesia dan pengaruhnya dalam kehidupan lingkungan terdekat. 4.4. Menyajikan hasil-hasil dan nilai-nilai budaya masyarakat praaksara Indonesia dan pengaruhnya dalam kehidupan lingkungan terdekat dalam bentuk tulisan. Hasil-hasil kebudayaan yang terdapat pada penelitian ini 3 arca manusia dan 1 batu datar, nilai-nilai yang terkandung di dalam penelitian ini ialah nilai sejarah, nilai budaya, dan nilai modernitas.

Situs Padang Perigi terdapat megalith 3 arca manusia dan 1 batu datar, di dalam 3 arca manusia dan 1 batu datar terkandung nilai-nilai sejarah dan budaya yang dapat menjadi materi pembelajaran sejarah nasional. Bahasan ini masuk ke dalam materi sejarah kelas 10 semester 1 mengenai zaman prasejarah khususnya masuk ke dalam materi pokok kebudayaan zaman praaksara. Situs Padang 
Perigi ini menambah khazanah pengetahuan sejarah mengenai peninggalan-peninggalan hasil kebudayaan zaman praaksara yang terdapat di Kabupaten Lahat.

\section{SIMPULAN}

Situs Padang Perigi memilki 3 arca manusia dan 1 batu datar yang terdapat keunikan tersendiri, di mana pada arca II dan III terdapat manik-manik dan kalung yang dipahatkan pada arca tersebut sehingga dari penelitian tersebut dapat diambil kesimpulan bahwa masyarakat pada masa itu sudah memiliki peradaban yang cukup tinggi karena sudah mengenal aksesoris serta fashion dalam berpakaian.

\section{DAFTAR PUSTAKA}

Andramartik, M. 2017. "Tabir Keagungan Leluhur, Jelajah Negeri Mengenal Budaya". Dalam Panoramic of Lahat, 2.

Iskandar, B. 2020. Lahat, Kota Wisata dengan Sejuta Megalith. SINDONews, 1.

Maryaeni. 2012. Metodelogi Penelitian Kebudayaan. Jakarta: PT Bumi Akasara.

Poesponogoro, M. D., \& Notosusanto, N. 2010. Sejarah Nasional Indonesia 1. Jakarta: Balai Pustaka.

Rr.Triwujani. 2018. Arca-Arca Megalitik. Jakarta: Yayasan Pustaka Obor Indonesia.

Sudaryadi, A. 2016. "Penyelamatan Arca-Arca Megalith Situs Padang Perigi Kabupaten Lahat". Dalam Siddhayatra, 13.

Sugiyono. 2017. Metode Penelitian Kualitatif, Kuantitatif dan R\&D. Bandung: Alfabeta. 


\section{KETENTUAN PENULISAN ARTIKEL JURNAL KALPATARU}

1. Naskah berbahasa Indonesia yang disempurnakan bertemakan kesejarah yang meliputi hasil penelitian sejarah, pengajaran sejarah dan penelitian kebudayaan.

2. Naskah harus asli dan belum pernah dimuat dalam media lain. Naskah dapat berupa hasil penelitian/artikel kajian konseptual yang ditulis oleh perorangan dan atau kelompok.

3. Naskah ditulis dengan cara-cara yang sesuai dengan ketentuan penulisan artikel ilmiah menggunakan bahasa Indonesia yang baku, berupa ketikan, beserta soft file dalam CD-RW atau dengan mengirimkan email pada redaksi jurnal Kalpataru dengan alamat jurnalkalpatarusejarah@gmail.com, spasi tunggal, jenis huruf arial narrow ukuran 12, dengan panjang naskah antara 8-15 halaman pada kertas A4.

4. Artikel hasil penelitian memuat:

JUDUL

Nama Penulis

Abstrak

A. PENDAHULUAN

B. METODE PENELITIAN

C. HASIL DAN PEMBAHASAN

D. SIMPULAN

DAFTAR PUSTAKA
: XXX (HURUF KAPITAL)

: (disertai jabatan, institusi, dan email)

: (Bahasa Indonesia yang memuat 100-200 kata diikuti kata kunci, dengan jenis huruf arrial narrow dan ukuran huruf 11 serta dicetak miring).

: (memuat latar belakang masalah, tinjauan pustaka secara ringkas, masalah penelitian, dan tujuan penelitian).

5. Artikel Kajian Konseptual memuat:

JUDUL

Nama Penulis

Abstrak

PENDAHULUAN

Sub Judul

Simpulan

DAFTAR PUSTAKA
: (berisi simpulan).

: (berisi pustaka yang dirujuk dalam uraian naskah).

6. Referensi sumber dalam teks artikel ditulis dengan menggunakan side note, contoh (Jalaludin, 1991:79); sementara penulisan daftar pustaka disusun dengan ketentuan. Nama pengarang. Tahun terbit. Judul (dicetak miring). Kota terbit: Nama Penerbit. Contoh: Koentjaraningrat. 2010. Manusia dan Kebudayaan di Indonesia. Jakarta: Djambatan. Daftar pustaka hanya memuat pustaka/sumber yang dirujuk dalam uraian dan disusun menurut abjad tanpa nomor urut.

7. Naskah yang dimuat akan disunting kembali oleh redaksi tanpa mengubah isinya.

8. Naskah yang ditolak (tidak bisa dimuat) akan dikirim kembali ke penulis dengan pemberitahuan tertulis dari redaksi atau melalui email.

9. Penulis yang naskahnya dimuat akan mendapat 1 (satu) majalah nomor yang bersangkutan.

10. Kontak person: Muhamad Idris (081271498618); Eva Dina Chairunisa (082281267851); Jeki Sepriady (085269261780). 